\title{
Are Kids Getting Smarter? Perceptions of Abilities in Lagos State
}

\author{
Ebinepre A. Cocodia \\ School of Arts \& Sciences, University of Notre Dame Australia, Sydney, Australia \\ Email: Ebinepre.cocodia@nd.edu.au
}

Received 3 June 2014; revised 1 July 2014; accepted 25 July 2014

Copyright (C) 2014 by author and Scientific Research Publishing Inc.

This work is licensed under the Creative Commons Attribution International License (CC BY). http://creativecommons.org/licenses/by/4.0/

c) (i) Open Access

\begin{abstract}
Individual abilities continue to be highly debated and researched issues in the fields of social and behavioral sciences. Findings from the Flynn Effect studies (Flynn, 1984, 1987) and Cocodia et al. (2003) suggest that average general intelligence is rising rapidly mainly due to environmental changes particularly in the Asian Tiger countries, while teachers in Australia reported that they did not believe intelligence had increased or decreased significantly in the last three decades. Thus the study theorized that rising intelligence is evident only where environmental changes have occurred more rapidly and recently. As such, Cocodia et al. proposed that rising intelligence may have finished in developed countries such as Australia. The present paper sought to explore further drawing from teacher responses in a developing country. Lagos, the former capital of $\mathrm{Ni}$ geria was selected as environmental changes have not occurred as rapidly as the Asian Tiger nations, nor is it a highly developed nation like Australia. Findings from the survey showed that more Nigerian teachers (58\%) perceived that student abilities had increased in the last three decades. The perception that students are more knowledgeable due to more access to new technology was also reported. Thus rising intelligence may also be evident in developing countries where environmental changes have not occurred as rapidly as reported elsewhere.
\end{abstract}

\section{Keywords}

Behavioral Science, Rising IQ, Intelligence, Perceptions, Student Ability, Developing Country, Nigeria

\section{Introduction}

There is increasing interest in the effects of rapid environmental changes on human ability and subsequently human intelligence. Such changes include technological advancement, the shift from third world to first and the transformations from rural to urban environments (Greenfield, 1998; Schooler, 1998). Interest in the fields of 
intelligence and rising IQs has been sparked by the Flynn Effect studies (Flynn, 1984, 1987). Flynn reported that IQ scores have been increasing steadily worldwide. Hence researchers began to question whether rising IQ scores indicate that average general intelligence is indeed rising (Cocodia, Kim, Shin, Kim, Ee et al., 2003; Neisser, 1997). Researchers including Flynn argued that it is not so, suggesting that humans are only getting better at taking IQ tests. Others proposed that it does and links rising IQ scores to rapid environmental changes such as the move from rural to urban communities and more recent technological advancement (Greenfield, 1998; Schooler, 1998). For instance, Schooler, 1998: pp. $74-75$ put it this way.

"If technical and economic development leads to more complex environments, such increased environmental complexity should result in higher levels of intellectual functioning".

In essence, Flynn's milestone study prompted new investigations into the phenomena of rising intelligence in more complex environments (e.g. Cocodia, Kim, Shin, Kim, Ee et al., 2003; Howard, 1999, 2001; Teasdale \& Owen, 1994). In a study conducted in Australia, Howard (2001) asked secondary school teachers if they perceived that students are brighter today compared to twenty years ago. Howard also asked teachers if they observed any changes in average general abilities. More teachers in Australia said no, reporting that they believe average general intelligence (Spearman's $g$ ) has stayed the same. Significantly, teachers complained that motivation to do work has declined. This is quite consistent with reports on declining motivation at the onset of adolescence (Ames, 1992; Ames \& Ames, 1984; Anderman \& Maehr, 1994). Howard concluded that this may be “masking” rising intelligence.

Cocodia, Kim, Shin, Kim, Ee et al. (2003) replicated the Howard (2001) study. The main difference between both studies is that Howard surveyed Australian secondary school teachers who have been teaching for twenty years, where Cocodia et al. surveyed primary school teachers in Singapore, Korea and Australia who have been teaching for up to thirty years. Cocodia et al. argued that formal education setting is the most appropriate place to search for any real changes in students' abilities over time. In addition they pointed out that primary school is a good place to seek out teachers' perceptions as motivation to study may be higher among this age group. Furthermore, the authors theorized that rising intelligence may be more obvious where environmental changes and the shift from third world to first occurred more rapidly and recently such as in the Asian tigers (Singapore and Korea). Perceptions of primary school teachers was sought in key areas such as reading ability, writing ability, general knowledge and general ability to do schoolwork. Teachers were also asked if they noticed any significant increases in the presence of very bright students, general intelligence, and motivation in school settings. The study reported that teachers in the Asian Tiger countries perceived that general intelligence and other key abilities have increased significantly in the last 30 years. These may be due to a more complex environment and technological advancement. However, perceptions in Australia reported no significant rise in average general intelligence. Hence, the researchers concluded that increases may not be noticeable because Australia is a Western economy where technological advancement occurred much earlier than the Asian tigers where it has taken place more recently and rapidly. In addition, the researchers argued that rising $g$ may have peaked much earlier in developed nations such as Australia. Unexpected, more teachers in all surveyed countries complained that motivation to do work has declined. In summary, the previous study showed that more teachers in Singapore (83\%) and Korea (61\%) perceived that average general intelligence have increased, while more Australian teachers $(71 \%)$ perceived that average general intelligence stayed the same.

\section{Current Study}

The aim is to build upon findings of the Cocodia et al. (2003) study. Two questions emerged based on the previous study:

1) Does the perceived rise in average intelligence imply that average general intelligence is evident only where technological change has occurred more rapidly?

2) Will average general ability remain the same in developing nations?

Thus, the present study did replicate the Cocodia et al. study in Nigeria, where environmental changes have not occurred as rapidly as the Asian Tiger countries.

\section{Methodology}

\subsection{Sample}

In Nigeria, primary school goes up to age 11. Primary school teachers in Lagos metropolitan area were surveyed. 
The sample consisted of only those teachers who began their first full-time teaching job in 1981 or earlier were included in the survey. The country is a developing nation that is not highly industrialized like Australia, and has not gone through rapid change like Singapore and Korea.

Nigeria situated in Western African is gained independence from British colonial rule since 1960. Although it is a developing economy, education is highly valued in Nigeria with parents spending sizeable amounts of their income on after-school tutoring for their children. However, a growing gap between the rich and the poor consequently eliminates a middle class. Students now spend up to eight hours in school unlike some years ago when they spent a standard five hours in primary schools. University enrolments have doubled in the last fifteen to twenty years with limited spaces available. Unfortunately technological advancement in Nigeria is moving very slowly and has not caught up with the population demand (Abdi, 2003; Cocodia, 2003; Woolman, 2001). It was therefore logical to seek out perceptions of students' abilities.

\subsection{Procedure and Instrument}

Ethics clearance was obtained from the University of New South Wales Australia's ethics committee. The researcher used qualitative and quantitative research methods. Questionnaires were administered to teachers in the public school system and independent schools in Lagos state. The questionnaires consisted of two sheets pages same as that used by Cocodia et al. (2003) and Howard (2001). The first section was for teachers who began teaching in 1981 or earlier while the second section was for those who began teaching in 1971 or earlier. This enabled the researcher to compare reports of the two groups of teachers. The final section was the free response section where teachers were asked to write freely about any observations or comments they wished to share. The questionnaire included nine items per sheet. Teachers were asked if they perceived that certain abilities have increased, decreased or stayed the same in the last 20 to 30 years. These abilities include: general intelligence, reading and writing, general knowledge, street-smartness (ability to deal with practical matters), ability to do school work and motivation to do work. As done with the previous survey, the questionnaire asked teachers if the proportion of very bright (e.g. gifted) students in each class has increased, decreased or stayed the same. Teachers were also asked if the presence of students with learning difficulties has increased, decreased, or stayed the same.

Principals and head teachers were contacted directly as the process of mail outs does not work successfully here. Teachers in Nigeria were given a questionnaire exactly like that completed by teachers in Australia, Singapore and Korea. The principals returned all completed questionnaires directly to the researcher. They were also instructed to involve only those teachers who have been teaching for up to 20 years or more. The teachers were not informed about the nature of the study until the questionnaires were completed and returned to the school principal. Although there are three major languages spoken (Hausa, Ibo and Yoruba), the lingua franca in the country is English. The teachers were therefore asked to complete the questionnaires in English.

\section{Result}

A total of 131 questionnaires were filled out correctly and included in the data analysis. Five questionnaires had to be discarded as they were not filled out properly.

1) Frequency distribution and chi square test of surveyed Nigerian teachers' response on each item.

Table 1 represents the perceptions of Nigerian teachers. Significantly, more teachers ( $n=75,57.3 \%$ ) reported that general intelligence has increased. This is consistent with teacher perceptions in Korea and Singapore (Cocodia et al., 2003). The chi square statistics $\left(\chi^{2}=46.96, \mathrm{df}=2, p<0.05\right)$ support this finding. Fewer teachers reported that reading and writing abilities have increased $(n=52,39.7 \%)$. The chi square statistics $\left(\chi^{2}=34.55\right.$, $\mathrm{df}=2, p<0.05)$ indicates that teacher perceptions are quite significant. Nigerian teachers $(\mathrm{n}=95,72.5 \%)$ perceived that general knowledge has increased. The chi square statistics $\left(\chi^{2}=97.11, \mathrm{df}=2, p<0.05\right)$ indicates that Nigerian teacher perceptions of increases in general knowledge is very significant. Similarly, Cocodia et al. (2003) found that teachers in Korea, Singapore and Australia reported that general knowledge has increased. More Nigerian teachers $(n=95,72.5 \%)$ reported that students are more street-smart. The chi square statistics $\left(\chi^{2}\right.$ $=96.06, \mathrm{df}=2, p<0.05)$ reinforces the reported rise. Only some Nigerian teachers $(\mathrm{n}=37,28.2 \%)$ perceived that ability to do school work has increased. The chi test statistics $\left(\chi^{2}=71.19, \mathrm{df}=2, p<0.05\right)$ supports the teacher reports. A significant number of teachers $(n=55,42 \%)$ perceived that students are very bright compared to twenty or thirty years ago. The chi square statistics supports this rise $\left(\chi^{2}=17.65, \mathrm{df}=2, p<0.05\right)$. This result 
Table 1. Goodness-of-fit Chi-square test of teachers who perceive that abilities have increased in Nigeria.

\begin{tabular}{cccc}
\hline Variable & $\begin{array}{c}\text { Observed Frequency } \\
(\mathbf{O})\end{array}$ & $\begin{array}{c}(\mathbf{O}-\mathbf{E})^{\wedge \mathbf{2}} \\
(\mathbf{O}-\mathbf{E})^{\wedge} \mathbf{2} / \mathbf{E}\end{array}$ \\
\hline General Intelligence & 75 & 961 & 21.84 \\
Read \& Write & 52 & 64 & 1.45 \\
General Knowledge & 95 & 2601 & 59.11 \\
Street Smartness & 95 & 2601 & 59.11 \\
School Work & 37 & 49 & 1.11 \\
Very Bright & 55 & 121 & 2.75 \\
Learning Difficulties & 65 & 441 & 10.02 \\
Motivation & 55 & 121 & 2.75 \\
Chi-squared & & & 158.15 \\
\hline
\end{tabular}

df $=7, X 2=158.1591, p<0.05$.

is comparable to perceptions of teachers in Korea (Cocodia et al., 2003). Surveyed Nigerian teachers reported that the presence of students with learning difficulties $(n=65,49.6 \%)$ has increased. The chi square statistics $\left(\chi^{2}\right.$ $=19.34, \mathrm{df}=2, p<0.05)$ supports this finding. This is comparable to perceptions of teachers in the Cocodia et al. (2003) study with the exception of Singapore that reported that the presence of LD (learning difficulties) students has increased. Surveyed Nigerian primary school teachers $(n=70,53 \%)$ reported declining motivation to do work. The chi square statistics $\left(\chi^{2}=51.31\right.$, $\left.\mathrm{df}=2, p<0.05\right)$ supports this finding. This is similar to teacher reports from Korea and Australia (Cocodia et al., 2003) who also reported that motivation to learn has declined.

2) Percentage of surveyed teachers reporting perception of change between 1981-2010 and 1971-2010.

Table 2 shows percentages in different categories of all respondents (1981 teachers, $n=131)$ and the subset of teachers who began teaching in 1971 or earlier $(n=50)$. More 1971 teachers $(n=50,68 \%)$ perceived that general intelligence has increased with the 1981 teachers $(n=131,57 \%)$ reporting that general intelligence has increased. More of the 1971 teachers $(n=50,60 \%)$ reported that reading and writing ability has increased with some of the 1981 teachers $(n=131,40 \%)$ perceiving an increase. Both 1971 teachers $(n=50,70 \%)$ and 1981 teachers $(\mathrm{n}=131,73 \%)$ reported that general knowledge has increased. The 1971 teachers $(\mathrm{n}=50,80 \%)$ and 1981 teachers $(n=131,61 \%)$ perceived that street smartness has increased significantly in the last twenty to thirty years. Surveyed 1971 teacher reported that ability to do schoolwork has decreased (n $=50,60 \%$ ). The 1981 teachers also reported declining ability to do schoolwork ( $n=131,66 \%)$. Many of the 1971 teacher reported that the presence of very bright students has increased $(n=50,60 \%)$. The 1981 teachers also reported an increase in very bright students $(n=131,42 \%)$. The 1971 teachers reported that that are fewer students with learning difficulties $(n=50,22 \%)$, while the 1981 teachers perceived an increase $(n=131,50 \%)$. More of the 1971 teachers perceived that motivation has declined $(n=50,78 \%)$, with the 1981 teacher reports showing a decrease in motivation to work $(n=131,53 \%)$.

\section{3) Free response section: Nigeria.}

The free response section encouraged teachers to share any personal opinions or observations regarding any perceived changes over time. Only some of the comments have been included in Table 3. The qualitative analysis presented here involved selecting those comments which bore similar themes. The free response section provided a diverse range of responses from the teachers. Certain themes emerged and within these themes were significant categories. These are described as follows:

a) Environmental influence on abilities: Nigerian teacher comments revealed patterns which indicated that teachers have linked some positive influences of the environment to increases in average general abilities. Three categories emerged in relation to this aspect of the study. More Nigerian teachers observed that:

- General living conditions have improved significantly;

- Improvements in the school curriculum has influenced average general abilities;

- More access to multimedia, computers and new technology.

b) Negative Environmental influence on abilities: teacher comments on the negative impact of environmental factors on abilities revealed three distinct categories. Teachers observed that: 
Table 2. Percentage of surveyed teachers reporting perception of change between 2002-1981 and 2002-1971.

\begin{tabular}{cccc}
\hline & Increased & Decreased & Stayed Same \\
\hline General Intelligence & $57(68)$ & $34(10)$ & $8(22)$ \\
Reading \& Writing & $40(60)$ & $50(38)$ & $10(2)$ \\
General Knowledge & $73(70)$ & $23(20)$ & $5(10)$ \\
Street Smartness & $61(80)$ & $22(12)$ & $17(8)$ \\
Schoolwork & $28(36)$ & $66(60)$ & $6(4)$ \\
Very Bright & $42(60)$ & $42(20)$ & $16(20)$ \\
Learning Difficulties & $50(22)$ & $32(66)$ & $18(12)$ \\
Motivation & $42(20)$ & $53(78)$ & $5(2)$ \\
\hline
\end{tabular}

1971, $\mathrm{n}=50 ; 1981, \mathrm{n}=131$ (This includes all teachers).

Table 3. Actual numbers and percentages of all surveyed teachers' perception of change in student ability.

\begin{tabular}{|c|c|c|c|c|c|c|}
\hline & \multicolumn{2}{|c|}{ Increased } & \multicolumn{2}{|c|}{ Decreased } & \multicolumn{2}{|c|}{ Stayed Same } \\
\hline & $\mathrm{n}$ & $\%$ & $\mathrm{n}$ & $\%$ & $\mathrm{n}$ & $\%$ \\
\hline General Intelligence & 75 & 57.3 & 45 & 34.4 & 11 & 8.4 \\
\hline Read \& Write & 52 & 39.7 & 66 & 50.4 & 13 & 9.9 \\
\hline General Knowledge & 95 & 72.5 & 30 & 22.9 & 6 & 4.6 \\
\hline Street Smartness & 95 & 72.5 & 29 & 22.1 & 7 & 5.3 \\
\hline School Work & 37 & 28.2 & 86 & 65.6 & 8 & 6.1 \\
\hline Very Bright & 55 & 42.0 & 55 & 42 & 21 & 16 \\
\hline Learning Difficulties & 65 & 49.6 & 42 & 32.1 & 24 & 18.3 \\
\hline Motivation & 55 & 42.0 & 70 & 53.4 & 6 & 4.6 \\
\hline
\end{tabular}

- Motivation to learn has decreased in the past twenty to thirty years;

- Parental/home discipline has decreased which in turn they blame on lack of willingness to do schoolwork;

- Lack of adequate infrastructure/resources in schools hinders the development of student abilities;

- Declining teacher motivation has impacted student abilities negatively.

c) Increased average general abilities: the free response data indicated that Nigerian teachers' perceived general abilities may have increased significantly compared to twenty or thirty years ago. Teachers commented that students are brighter, inquisitive, creative, and more intelligent with fewer LD students showing up in mainstream classes. They also noted that students are now street smart and reading and writing abilities have increased. However, as with the teacher observations of the Cocodia et al. study, the Nigerian teachers complained that students get bored when doing required work and need constant entertainment.

\section{Free response.}

\section{Nigeria}

Average abilities have increased but students find it hard to stay on task.

More children have personal computers at home unlike 20 years ago thus taking advantage of new technological development.

Teaching the kids is more fun and pleasant... Sometimes you get taught by them...

Motivation to learn is declining.

More intelligent children are showing up in school... They however find it difficult to settle down and do some work.

Teachers are not motivating students to work.

Lack of discipline at home is affecting student performance in class.

More knowledgeable children due to exposure to internet, cable TV, etc.

... Kids are brighter; they pick up new information faster unlike 20 years ago.

Kids want to be told what to do without making any effort on their own.

Fewer learning disabled or special needs kids in classroom.

Reading and writing skills has improved.

Children are now been exposed to more practical work thanks to school curriculum improvements.

Kids are more inquisitive.

Government needs to improve educational infrastructure.

...more street smart 
In summary, the free response section showed that Nigerian teachers perceived that reading and writing skills have improved which in turn have influenced student ability to express themselves successfully in school. This is comparable to perceptions of teachers in Singapore, Australia and Korea. Teacher responses in Nigeria also share other similarities with that of the Cocodia et al. study. Teachers have attributed the rise in average ability to technological advancements and more access to information. This is quite consistent with the previous study where teachers have linked increasing abilities to (among other factors) new technology and more access to information. However, teachers in Nigeria reported that they now observe fewer students with learning difficulties (LD) in mainstream classes when compared to thirty years ago. This is quite consistent with more recent educational policy developments in Nigeria. The federal and state government's ministry of education provides separate learning facilities for LD students.

\section{Discussion and Conclusion}

Change in Nigeria has occurred at a slower pace compared to the Asian Tiger nations. However, the teacher survey indicated that the environmental changes in Nigeria are significant and in some cases just as noticeable as changes in Australia, Korea and Singapore. For instance up to $60 \%$ of the population now has more access to modern technology such as computers compared to say 30 years ago (UNESCO, 2001). Also between 1987 and 1999, the Federal Ministry of Education introduced new educational policies that involved the integration of computer technology in curriculum and classroom practice (FME, 2005).

It is likely that more access to education and knowledge may be a major factor influencing general intelligence levels. In the last five decades, the Nigerian government has ensured that the population has more access to schooling by making the first nine years of schooling compulsory for all. The government's Universal Primary Education program of the 1970s and the 1999 Universal Basic Education scheme helped guarantee that primary education is free and accessible where it previously was neither free nor easily accessible. However the free response section showed that teachers complain that government still needs to improve on educational facilities in the public education sector. The neglects of certain sectors such as education have been linked to sporadic political and economic instability (Soyinka, 1996; Ikejiani, 1965; Nwagwu, 1997) which has plagued the country since independence, labeling it a developing nation. However continuous effort has been made with the development of new literacy and numeracy programs (Nigerian Education Website, 2003). This has helped to reduce illiteracy levels with the percentage of literate males rising from 59\% in 1990 to $72 \%$ in 2000 (UNICEF, 2001). These educational developments which have occurred in the last four to five decades may be responsible for some of the reported perceptions. For instance, more of the 1971 teachers (Table 2) perceived that general intelligence (68\%) and reading and writing (60\%) ability have increased significantly.

In Nigeria, the emphasis placed on education has led to a rapid increase in school enrolments with more people pursing further and tertiary education. This demand has led to the establishment of more universities. For instance, in the 1960s there were only five universities in Nigeria. This number has increased to 35 which is the largest number of universities within any country in Africa. For this reason, Abdi (2003) describes Nigeria as the "powerhouse" of sub Saharan Africa. With more places available at the university level, the last four decades has seen more people reaching higher levels of educational attainment. Williams (1998) points out that increasing educational attainment in any society will influence childrearing practices, home environment and parental attention. This suggests increasing educational attainment in Nigeria may be pushing average general intelligence levels up regardless of its status as a developing nation. Vernon (1969) argued that more schooling does influence intelligence levels. The teacher survey lends support to this theory suggesting that teachers are now noticing increases in intellectual levels.

The current investigation indicates that rising intelligence is impacting in formal education settings. This suggests that average general intelligence is indeed increasing in Nigeria. The environmental changes which are occurring in this country may be influencing intellectual levels. Teachers surveyed by Cocodia et al. and Howard (2001) complained of decreasing motivational levels. Similarly teachers in Nigeria reported decreases in student motivation to do work. The Cocodia et al. study suggested that it may be linked to the constant need for entertainment amongst children today. Even with the reported decline in motivation, teachers in Nigeria still perceive that general intelligence is rising. This contrasts with Australisan teacher perceptions where the researchers proposed that teachers are unable to perceive rising intelligence because declining motivation may be masking $g$. 
Significantly, prior speculation that rising $g$ which may only be detectable where rapid environmental development has occurred has been dispelled by the results of this study. The Nigerian survey data suggests that no matter how small or large changes it may have, it is indeed noticeable and may impact intelligence levels. Also significant is that teachers in all four countries surveyed suggested that technological advancement and a more visual environment may be influencing student ability particularly in subjects which require high levels of visuospatial ability. Researchers have proposed that the Flynn effect is occurring due to increases in visuospatial abilities (Greenfield, 1998; Teasdale \& Owen, 1994).

There are limitations where the present study is concerned. Firstly, the major limitation as with any study conducted using a survey method is that it relies on a self-report method of data collection. Inaccuracies in the date may occur due to misunderstanding of the question or even a poor memory.

Secondly, the sample consisted of only those teachers in the Lagos state government school system and private, independent schools in Lagos. Other state and regional school boards in the country were not included in the study.

Further studies may investigate teacher perceptions in other developing nations in Africa, South America and Asia to present a clearer comparison with the result of the current study. In addition, longitudinal data collection and analysis of examination results in key learning areas such as in science and mathematics if available may have given a much more concise picture of students' abilities over the last twenty to thirty years.

\section{References}

Abdi, A. A. (2003). Searching for Development Education in Africa: Select Perspectives on Somalia, South Africa and Nigeria. International Education Journal, 4, 192-200.

Ames, C. (1992). Classrooms: Goals, Structures, and Student Motivation. Journal of Educational Psychology, 84, $261-271$. http://dx.doi.org/10.1037/0022-0663.84.3.261

Ames, C., \& Ames, R. (1984). Systems of Student and Teacher Motivation: Toward a Qualitative Definition. Journal of Educational Psychology, 76, 535-556. http://dx.doi.org/10.1037/0022-0663.76.4.535

Anderman, E. M., \& Maehr, M. L. (1994). Motivation and Schooling in the Middle Grades. Review of Educational Research, 64, 287-309. http://dx.doi.org/10.3102/00346543064002287

Cocodia, E. A. (2003). Teacher Perceptions and Examination Performance. Paper Presented at Hawaii International Conference for Social Sciences, June 12th-15th, Honolulu, HI.

Cocodia, E. A., Kim, J., Shin, H., Kim, J.W., Ee, J., Wee, M., \& Howard, R. W. (2003). Evidence That Rising Population Intelligence Is Impacting in Formal Education. Personality and Individual Differences, 35, 797-810.

http://dx.doi.org/10.1016/S0191-8869(02)00284-2

Federal Ministry of Education (FME) (2005). Education in Nigeria. Retrieved: February 16, 2005, Online. http://www.fmegovng.org/

Flynn, J. R. (1984). The Mean IQ of Americans: Massive Gains 1932 to 1978. Psychology Bulletin, 95, 29-51. http://dx.doi.org/10.1037/0033-2909.95.1.29

Flynn, J. R. (1987). Massive IQ Gains in 14 Nations: What IQ Tests Really Measure. Psychology Bulletin, 101, 171-191. http://dx.doi.org/10.1037/0033-2909.101.2.171

Howard, R. W. (1999). Preliminary Real-World Evidence That Average Human Intelligence Really Is Rising. Intelligence, 27, 235-250. http://dx.doi.org/10.1016/S0160-2896(99)00018-5

Howard, R. W. (2001). Searching the Real World for Signs of Rising Population Intelligence. Personality and Individual Differences, 30, 1039-1058. http://dx.doi.org/10.1016/S0191-8869(00)00095-7

Ikejiani, O. (1965). Education and Tribalism. In I. O. Ikejiani (Ed.), Education in Nigeria (pp. 82-132). New York: Praeger.

Neisser, U. (1997). Rising Scores on Intelligence Tests. American Scientist, 85, 440-447.

Nigerian Education Website (2003). Education in Nigeria. [Online] www.onlinenigeria.com/education/

Nwagwu, C. (1997). The Environment of Crisis in the Nigerian Education System. Comparative Education, 33, 87-96. http://dx.doi.org/10.1080/03050069728659

Schooler, C. (1998). Environmental Complexity and the Flynn Effect. In U. Neisser (Ed.), The Rising Curve: Long-Term Gains in IQ and Related Measures (pp. 66-79). Washington, DC: American Psychological Association.

Soyinka, W. (1996). The Open Sore of a Continent: A Personal Narrative of the Nigerian Crisis. New York: Oxford University Press.

Teasdale, T. W., \& Owen, D. R. (1994). Thirty-Year Secular Trends in Cognitive Abilities of Danish Male School Leavers at 
a High Educational Level. Scandinavian Journal of Psychology, 35, 328-335. http://dx.doi.org/10.1111/j.1467-9450.1994.tb00957.x

United Nations Educational, Scientific, \& Cultural Organisation [UNESCO] (2001). Regional Report on Sub-Saharan Africa. Retrieved 5 June 2001. http://www.uis.unesco.org/Library/Documents/ssa01-en.pdf

Vernon, P. E. (1969). Intelligence and Cultural Environment. London: Methuen. 
Scientific Research Publishing (SCIRP) is one of the largest Open Access journal publishers. It is currently publishing more than 200 open access, online, peer-reviewed journals covering a wide range of academic disciplines. SCIRP serves the worldwide academic communities and contributes to the progress and application of science with its publication.

Other selected journals from SCIRP are listed as below. Submit your manuscript to us via either submit@scirp.org or Online Submission Portal.
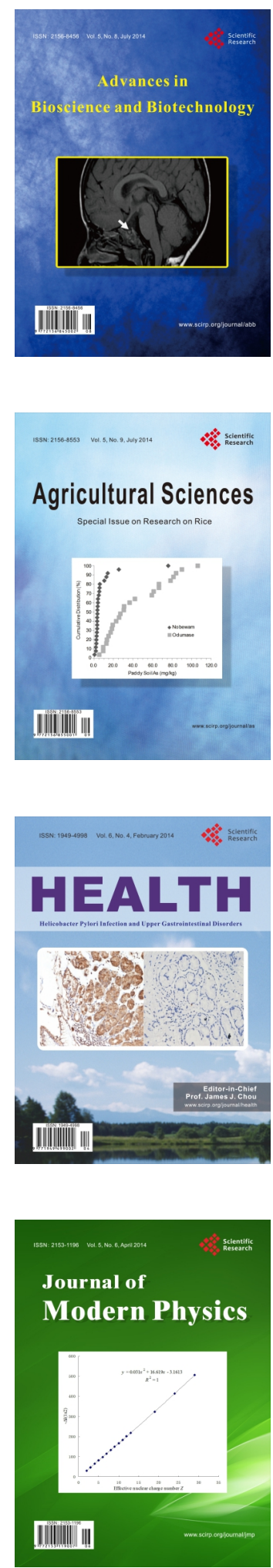
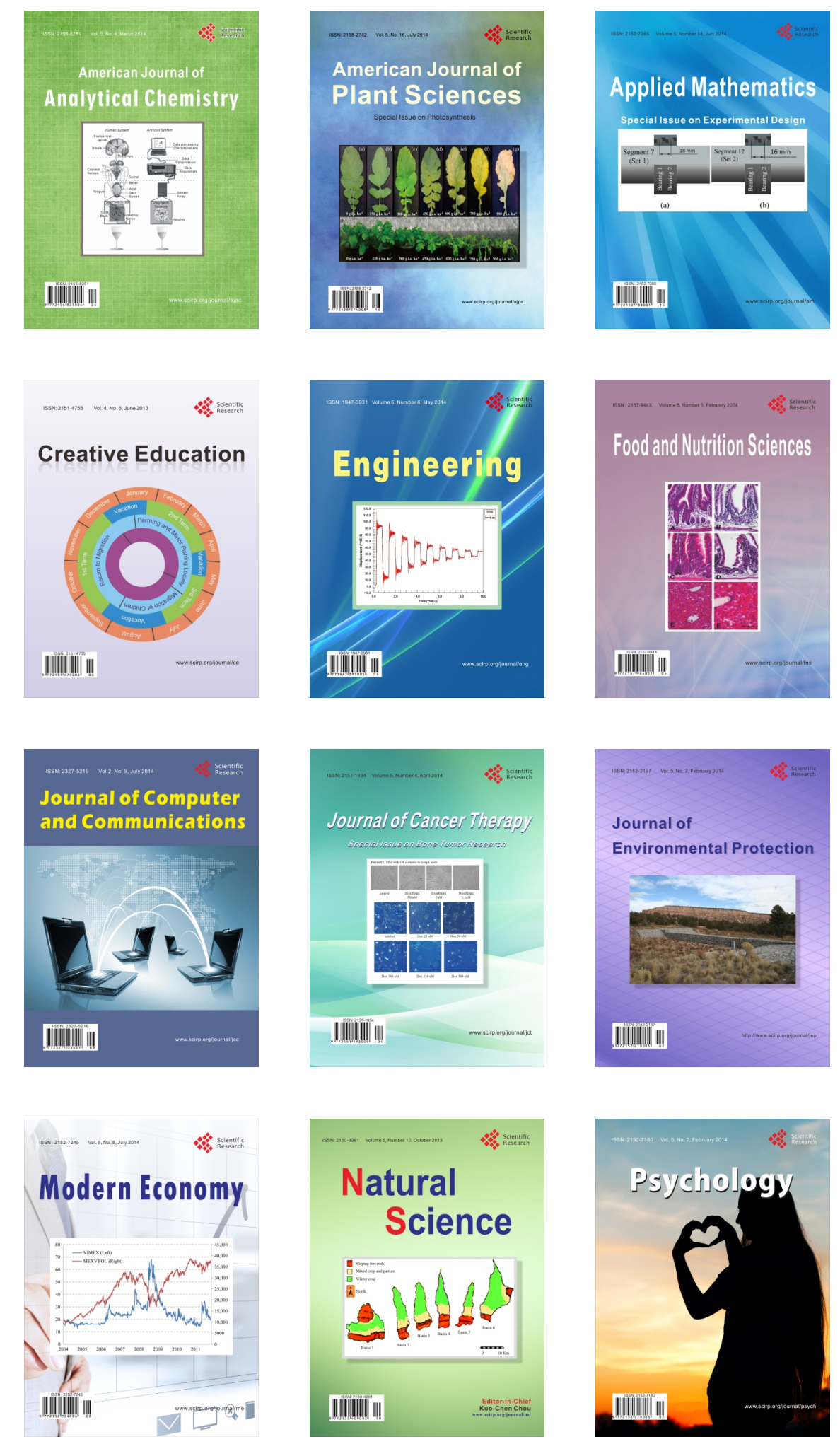